\title{
High level expression and characterization of a novel thermostable, organic solvent tolerant, 1,3-regioselective lipase from Geobacillus sp. strain ARM.
}

\begin{abstract}
The mature ARM lipase gene was cloned into the pTrcHis expression vector and overexpressed in Escherichia coli TOP10 host. The optimum lipase expression was obtained after $18 \mathrm{~h}$ post induction incubation with $1.0 \mathrm{mM}$ IPTG, where the lipase activity was approximately 1623 -fold higher than wild type. A rapid, high efficient, one-step purification of the His-tagged recombinant lipase was achieved using immobilized metal affinity chromatography with $63.2 \%$ recovery and purification factor of 14.6. The purified lipase was characterized as a high active (7092Umg -1), serine-hydrolase, thermostable, organic solvent tolerant, 1,3-specific lipase with a molecular weight of about $44 \mathrm{kDa}$. The enzyme was a monomer with disulfide bond(s) in its structure, but was not a metalloenzyme. ARM lipase was active in a broad range of temperature and $\mathrm{pH}$ with optimum lipolytic activity at $\mathrm{pH} 8.0$ and $65^{\circ} \mathrm{C}$. The enzyme retained $50 \%$ residual activity at $\mathrm{pH} 6.0-7.0,50^{\circ} \mathrm{C}$ for more than $150 \mathrm{~min}$.
\end{abstract}

Keyword: Lipase; Thermostable; Organic solvent tolerant; 1,3-regioselective; Expression. 